\title{
No new fast-food outlets allowed! The effect of local area planning policy on the healthiness of the local food environment
}

\author{
V. Albani ${ }^{1}$, H. Xiang ${ }^{1}$ and H. Brown ${ }^{1,2}$ \\ ${ }^{1}$ Population Health Sciences Institute, Newcastle University, Newcastle upon Tyne, UK and \\ ${ }^{2}$ Finnish Institute for Health and Welfare, Helsinki, Finland
}

Obesity is a complex health issue that stems from a variety of causes ${ }^{(1,2)}$. One critical determinant of obesity is the food environment, in particular fast food outlets (FFOs) and the role they play in the positive relationship between the consumption of high-calorie foods and obesity ${ }^{(3)}$. In England, local authorities (local government) can deploy planning permission policies to restrict the number of new FFOs in an area, e.g, around secondary schools, in areas with already high proportion of FFOs and in areas with a significant proportion of the population classified as overweight or obese ${ }^{(4)}$. In 2015, Gateshead Council, a deprived local authority in the North East of England, implemented all the above types of planning guidance, effectively imposing a blanket ban on new FFOs. This study explored the effectiveness of this blanket ban in changing the local food environment. Our hypothesis was that this approach would reduce in the short term the density and proportion of fast-food outlets compared to other types of food outlets.

We employed a causal difference in differences estimation approach comparing the FFOs density and proportion in local neighbourhoods (LSOAs) in Gateshead (treated, $\mathrm{n}=109$ ) with matched LSOAs in the North East of England without FFO planning guidance in place (controls, $n=109$ ), before and after 2015. Treated and control LSOAs were matched in terms of time-constant local characteristics using PSM with 1:1 nearest neighbor matching. Yearly LSOA-level data from 2012 to 2019 on FFO density per 100,000 residents, and data on the proportion of FFO over the total number of "restaurant/café/canteens", FFOs, "pub/night club/bars", and supermarkets was estimated from the UK Food Standards Agency Food Hygiene Rating Scheme (FSA FHRS). The FSA FHRS is an administrative dataset which records all food outlets in an area as part of statutory environmental health inspections. Regressions controlled for density of other types of food outlets, and year- and LSOA-fixed effects.

In 2012, there were 206 FFOs in Gateshead and 217 in the control LSOAs. In the four years after the implementation of the blanket ban, there were on average fewer $(17.5$ per 100,000 residents; $\mathrm{p}<0.01)$ FFOs in Gateshead compared to other local areas not implementing any planning restrictions on new FFOs. The proportion of FFOs to other food outlets also decreased by $11 \%(\mathrm{p}<0.01)$.

Employing all three types of planning guidance restricting new FFOs led to a significant reduction in the density and proportion of fast-food outlets in Gateshead. Overall, this suggests that planning may be an effective tool to limit access to unhealthy foods in the local food environment, but a sweeping approach is needed. Future research should explore if reducing the number of fast-food outlets leads to lower obesity rates.

\section{References}

1. Frood S, Johnston L, Matteson CL et al. (2013) Curr Obes Rep 2, 320-326.

2. Currie J, DellaVigna S, Moretti E et al. (2010) Amer Econ J: Econ Pol 2, 32-63.

3. Keeble M, Burgoine T, White M et al. (2019) Health Place 57, 171-178. 